\title{
Global Equality of Opportunity as an Institutional Standard of Distributive Justice
}

\section{Daniel Butt, University of Bristol ${ }^{*}$}

We live in a world with a broad range of institutions whose actions affect the distribution of benefits and burdens both between and within particular political communities. As cooperation and interdependence between communities increases, so there is a greater need for overbridging institutions that regulate and control international interaction. We can expect both increases in the powers of existing international institutions and the development of significant new international institutions. Examples include international governmental bodies such as the General Assembly and Security Council of the United Nations and the Council of Ministers and European Parliament of the European Union (EU), international judicial bodies such as the European Court of Justice and the Inter-American Court of Human Rights, international trade organizations such as the World Bank, International Monetary Fund, and the World Trade Organization, and nongovernmental organizations, such as Oxfam or the Red Cross. By what standards should the decisions and actions of such institutions be assessed?

This chapter argues that international institutions should be guided by a cosmopolitan principle of global equality of opportunity (GEO), which holds that individuals should have access to opportunity sets of equivalent value regardless of 
their nationality. The central idea is that international justice requires international institutions to go further than the degree of intervention required by "sufficientarians," who accept only that we possess duties to raise those in other countries to some minimal level of well-being. The chapter defends a more demanding principle of global equality that seeks to remove egregious international inequalities of opportunity even when they apply to persons above the minimal sufficientarian threshold of well-being. This is a contentious claim. Global egalitarianism is controversial even on an abstract level - many deny that there is any sense in which justice requires an international redistribution of resources in keeping with the principle of equality. Things get even more difficult when we come to realworld policy claims: Here the advocate of GEO must confront skepticism as to the principle's practicality, both in terms of the desirability and the possibility of its implementation, and doubts as to the legitimacy of institutional intervention in its favor. This chapter does not respond to all such objections in detail, but it does sketch a version of GEO in which it could plausibly be said that it should - in an all-thingsconsidered sense - be promoted by existing international institutions.

\section{WHAT DOES IT MEAN TO SAY THAT INSTITUTIONS "SHOULD" IMPLEMENT PRINCIPLES OF DISTRIBUTIVE JUSTICE?}

The question whether and how political institutions should be guided by principles of distributive justice is a complex and contested one. It does not necessarily follow from the claim that, in an ideal world, individuals would have particular entitlements as a matter of distributive justice that agents in the real world should seek to make 
actual holdings closer to these ideal holdings. This is true both of individual agents and of political institutions. As an egalitarian, I may believe that society would be more just if some of my rich neighbor's property was redistributed to me. However, it does not necessarily follow from this that I am entitled to help myself to her possessions, or that others - be they everyday citizens, agents of the state, or representative legislative bodies - are morally entitled or required to transfer some of her property to me, or that my neighbor herself is morally required so to act. There are a number of different reasons why one might maintain that action seeking to bring the world closer to its ideal state should or need not be undertaken by any or all of the agents listed. Specifically, a claim that a given principle of distributive justice should or should not be implemented at the political level may be a response to one of three distinct questions:

1. What is the best philosophical account of principles of distributive justice?

2. Is it desirable, in practical terms, that these principles should be implemented?

3. Do political institutions act legitimately in seeking to implement these principles?

Much contemporary philosophical writing about distributive justice relates to the first question. Some writers think that the answer to the first is connected to the answer to the second; ${ }^{1}$ others see these as separate. ${ }^{2}$ One dispute concerns the status of justice. Some argue that justice is simply one desideratum of political activity. As such, a 
claim that a given course of action would lead to a more just outcome may give us a reason to perform the action but does not settle the issue, because there may be other competing reasons, derived, from example, from overall utility, or the needs of the worst-off members of society, which also need to be assessed. For others, considerations of justice should be formulated in such a way as to take such considerations into account; hence Rawls's claim that "justice is the first virtue of social institutions, as truth is of systems of thought."3 Regardless of how much pragmatism or pluralism one builds into one's principles of distributive justice in terms of Question 1, one will always have to consider the practical effects of their implementation before maintaining that they should be pursued in real-world, nonideal contexts.

The third question has sometimes been bracketed by political philosophers focusing primarily on questions of justice, though it has been extensively addressed by legal philosophers and democratic theorists. It can take two forms. The most familiar arises when we are confronted with a situation in which there appears to be a gap between what we believe to be the best course of action for society to follow, taking account of both normative requirements and considerations of practicality, and what a majority of the population believes the best course of action to be. ${ }^{4}$ When should those individuals charged with making decisions on behalf of society pursue their own favored alternative, and when should they defer to the views of the majority? The question's alternative form arises for those who believe that certain forms of political action should not be justified by reference to a single 
comprehensive account of the good, but should instead appeal to a wider range of different approaches to life. So Rawls's later work placed an emphasis on the justification of political action that affects constitutional essentials and questions of basic justice in terms of public reason, understood in terms of an overlapping consensus of reasonable comprehensive conceptions of the good. ${ }^{5}$

A claim that institutions should pursue distributive outcomes in an all-thingsconsidered sense must, then, engage with questions of normative desirability, of practicality, and of legitimacy. All questions need not be answered in the same wayit is quite coherent, for example, to maintain that a given institutional action is justified in an all-things-considered sense even though it is not legitimate.

Nonetheless, it must be shown why the action is of sufficient value to trump concerns of legitimacy. All of this can easily amount to a bias in favor of the status quo. Typically, it is harder to make such an argument in relation to transformative, as opposed to conservative, accounts of distributive justice. This is the type of hurdle that faces GEO. The cosmopolitan account of distributive justice upon which the account rests is controversial on three different levels. First, it is philosophically contentious as even an account of ideal-type justice. Second, it is often portrayed as impractical in the real world. Third, it appears to be radically divorced from the majority of real-world beliefs about how international institutions should act. We live in a world that is still predominantly characterized by the significance of state sovereignty over resources and borders. This principle of state sovereignty seems to have widespread popular support, and it is strongly rooted in contemporary 
understandings of international law. Is it really the case that cosmopolitan political theorists believe that international institutions in the real world should, here and now, be acting so as to promote global equality of opportunity? In what follows, I speak to each of these three concerns: first outlining GEO as an element of an ideal-type account of international distributive justice, second addressing concerns relating to its practical desirability and possibility, and finally briefly addressing the question of the legitimacy of institutional egalitarian interventions.

\section{WHAT IS THE BEST PHILOSOPHICAL ACCOUNT OF INTERNATIONAL DISTRIBUTIVE JUSTICE?}

The basic idea behind GEO is that we should show the same substantial concern for equality of opportunity at a global level as within a domestic context. Insofar as GEO maintains that boundaries between different peoples do not have moral significance, it is cosmopolitan; insofar as it maintains that individuals should have equal opportunities, it is egalitarian. Thus, GEO is a variant of cosmopolitan egalitarianism, but it only maintains that distributions should be equal to the extent that is necessary to ensure that different individuals have, in some specified sense, equal opportunities for flourishing. Just as there are different conceptions of equality of opportunity at a domestic level, so one might develop a range of different forms of GEO. A common distinction is between "formal" and "substantive" equality of opportunity. ${ }^{6}$ According to the former idea, equality of opportunity requires that desirable positions be open to all, and be filled on the basis of aptitude, so that the positions are allocated to those who are best able to perform the associated duties. This requirement does not 
scrutinize how different individuals come to possess the relevant aptitude, and so is seemingly compatible, for example, with an inegalitarian education system that provides a better education for some than others, making it relatively easier for some to gain desirable positions. Formal equality of opportunity is the approach that is most typically invoked in real-world contexts in relation to employment disputes, particularly in judicial contexts.

Substantive equality of opportunity goes further; it looks at the process by which the relevant aptitude is acquired. Insofar as this reflects factors for which the individual agents in question cannot be held responsible, substantive equality of opportunity judges ensuing inequalities to be unfair. So, for example, Rawls's account of fair equality of opportunity in A Theory of Justice rests upon a simple idea that many have taken to have immediate intuitive plausibility - that it is unfair if one's social circumstances, encompassing factors such as race, sex, and social class, affect one's ability to succeed in life. Richard Arneson describes the prescribed outcome of such an account as follows:

[I]f Smith and Jones have the same native talent, and Smith is born of wealthy, educated parents of a socially favored ethnicity and Jones is born of poor, uneducated parents of a socially disfavored ethnicity, then if they develop the same ambition to become scientists or Wall Street lawyers, they will have the same prospects of becoming scientists or Wall Street lawyers if [fair equality of opportunity] prevails. ${ }^{7}$ 
It should be understood that even the substantive account of equality of opportunity only goes a limited distance down the egalitarian road. As Samuel Freeman notes:

The idea of fair equal opportunity is rather narrow; it concerns the opportunities people have to compete for social positions and the legal powers they involve. We might, then, say it involves equal opportunity for powers and positions among "those who are at the same level of talent and ability, and have the same willingness to use them." This is quite different from the much broader distributive idea of equal opportunity for welfare endorsed by some luck egalitarians. ${ }^{8}$

Equality of opportunity argues that desirable positions should be allocated fairly according to some idea of merit, but we still need an account of the extent to which there should be a hierarchy of social positions, which confers benefits and prestige upon their bearers. A concern for substantive equality of opportunity will limit the degree of material inequality in society insofar as doing so is necessary to prevent some individuals from gaining an unfair advantage over others in the competition for desirable positions. Such an approach is likely to place restrictions on the extent to which individuals can transfer advantages to their children, either by direct transfers such as the inheritance of wealth or by providing privileged access to education or healthcare - Rawls argues that it places an obligation on the state to prevent "excessive accumulations of property and wealth" and to maintain "equal opportunities of education for all" $"$ - but it is still compatible with a range of more or less hierarchical ways of organizing the social order. 
This is not to say that the advocate of substantive equality of opportunity need condone particular models of social hierarchies and unequal reward distributions. Equality of opportunity need not be viewed as a complete theory of distributive justice; instead it can be seen as placing constraints on justifiable distributions - if there are to be inequalities, they should be attached to offices and positions open to all under conditions of fair equality of opportunity. A full account will have to refer to further principles of distributive justice to determine to what extent inequalities in the social order are to be permitted. Whereas some people will be willing to organize society as to maximize efficiency, for example, others may wish to trade off overall efficiency for equality, and so restrict or eliminate more and less desirable social positions. For Rawls, the difference principle answers this question: Inequalities are permitted, but only insofar as they benefit the least advantaged members of society. The point is that very different models of social hierarchy can accept the fair equality of opportunity principle. Rawls's second principle of justice, regulating inequalities, is as follows:

Social and economic inequalities are to be arranged so that they are both:

(a) to the greatest benefit of the least advantaged, consistent with the just savings principle, and

(b) attached to offices and positions open to all under conditions of fair equality of opportunity. ${ }^{10}$

Significantly, (b) is lexically prior to (a) here, so the fair equality of opportunity principle has priority over the difference principle. This leaves open the possibility 
that other principles could replace (a) in this formulation without infringing upon (b). So, for example, one could replace (a) with one of the following: (a1) to the greatest benefit of society as a whole in terms of aggregate utility; (a2) only permitted when necessary to prevent some members of society from falling below a threshold level of minimal well-being; or (a3) only permitted when necessary to protect the security of the community. Given the lexical priority of (b) over (a), all three of these replacements respect fair equality of opportunity.

Substantive equality of opportunity, then, only requires distributive equality insofar as the distribution of resources affects competition for desired positions. In broad terms, the advocate of equality of opportunity will be concerned with three categories of goods. In some cases, equality of opportunity will require equal distributions of goods. In others, it will require that all individuals have access to a sufficient degree of resource provision. Finally, in some cases equality of opportunity will allow inequalities, insofar as they do not affect competition for desirable positions. A commitment to substantive equality of opportunity limits the range of acceptable complete theories of distributive justice, and it means that one must be more egalitarian than a person who adopts a straightforward sufficientarian approach, which looks only at absolute and disregards relative levels of advantage, but its acceptance of distributive egalitarianism is limited.

Turning to the global level, we find that it is possible to put forward either formal or substantive variants of GEO. Both appear to be profoundly challenging to current international practice. The claim that careers should be "open to talents" 
seems antithetical to contemporary restrictions on immigration, which typically afford priority in employment to citizens of the country in question, or selected countries who are members of reciprocal agreements, as in the case of the EU. Substantive GEO goes even further, seemingly requiring significant material redistribution between different states if those persons of equal talent and motivation are to have equal chances of success in life. Both variants of GEO crucially rest upon what is perhaps the most powerful weapon is the cosmopolitan armory - the idea, which many find intuitively compelling, that there is something unfair about the fact that one's nationality - which is clearly, in Rawls's terms, arbitrary from a moral point of view - has such a critical impact on one's life prospects. The basic idea of substantive GEO in particular is that, at a global level, nationality is analogous to social class at a domestic level. The idea is put forward powerfully by Joseph Carens:

Citizenship in the modern world is a lot like feudal status in the medieval world.... To be born a citizen of an affluent country like Canada is like being born into the nobility (even though many belong to the lesser nobility). To be born a citizen of a poor country like Bangladesh is (for most) like being born into the peasantry in the Middle Ages. ${ }^{11}$

Many find the claim that there is something unjust about such a situation plausible, but it is important to appreciate that it does not follow automatically from an acceptance of fair equality of opportunity at a domestic level. Strikingly, Rawls himself does not extend the reach of his principles of distributive justice globally. He argues not for an international difference principle, but for a sufficientarian minimal 
duty of assistance to other peoples, with a cutoff point that comes into play when the people in question become self-sufficient. ${ }^{12}$ The key question here concerns what is sometimes called the "circumstances of justice." When do questions of distributive justice actually arise? For "nonrelational" theorists, the answer is straightforward principles of distributive justice apply to any and all moral persons, regardless of the nature and extent of interaction between them. ${ }^{13}$ Such a conclusion is undoubtedly controversial. Many writers argue that it is only when persons stand in a particular type of interactional relation with one another that questions of distributive justice, and so concerns of equality of opportunity, arise. "Relational" theorists have put forward a range of different accounts of how people can come to owe one another duties of distributive justice: possible candidates include regular interaction through politics or commerce, ${ }^{14}$ common subjection to coercive authority, ${ }^{15}$ and joint authorship of coercive law, ${ }^{16}$ among many others. Any relational theorist must answer two questions in connection with international justice. First, what is the form of relation between persons that would give rise to internationally applicable duties of distributive justice? Second, do we find such a form of relation in the real world? Answering the second question affirmatively commits one, at a theoretical level, to distributive cosmopolitanism. There are, then, multiple routes to distributive cosmopolitanism. One may advocate a nonrelational account of distributive justice, whereby the moral equality of persons leads to egalitarian distributive principles between persons regardless of whether there is any interaction between the persons in question. Alternatively, one may put forward a relational account whereby 
distributive principles only apply between persons who interact in a certain kind of way. The critical question for such accounts is therefore whether contemporary (or potentially historic) ${ }^{17}$ global interaction meets the specified relational threshold. If so, the door is open to an argument for GEO.

This, then, is the ideal lying behind GEO. Quite what it means in practice for GEO to obtain is a contentious issue. The most straightforward account is given by Darrel Moellendorf, and it directly relates to the Rawlsian account of fair equality of opportunity:

If equality of opportunity were realized, a child growing up in rural Mozambique would be statistically as likely as the child of a senior executive at a Swiss bank to reach the position of the latter's parent. ${ }^{18}$

This reference to the need for equal opportunity to achieve specific jobs has been much criticized, and the point is more generally expressed in terms of individuals having equal opportunity sets, so that they have access to comparably valuable opportunities, even if they do not possess identically the same set of opportunities. ${ }^{19}$ So, for example, Simon Caney summarizes GEO as follows:

Global equality of opportunity requires that persons (of equal ability and motivation) have equal opportunities to attain the positions valued in every society. $^{20}$

Sylvie Loriaux's conception is broadly similar: 
[A] plausible version of global equality of opportunity can be constructed, which demands that equally talented and motivated persons who participate in the global economic order should have a roughly equal chance to benefit from this order if they so choose, irrespective of the society to which they belong. ${ }^{21}$ Much more could be said about the differences between these accounts; for now, it will suffice to note that an advocate of GEO must maintain that, in some sense, individuals of equal talent should have access to equal opportunity sets, regardless of their nationality. Such advocates typically draw on the capabilities approach of writers such as Amartya Sen and Martha Nussbaum to assess what is needed for GEO to obtain. ${ }^{22}$ Again, we might differentiate between three categories of capabilities: those whose provision needs to be provided equally if opportunity is to be equal; those whereby a minimal level of provision is necessary for opportunities to be equal; and those where international inequalities seem largely insignificant. The crucial point is that GEO does not require that international redistribution be so extensive as to leave all states equally well off in terms of, for example, per capita GDP. For some capabilities, such as education and health, it does seem necessary that provision in different states be of a comparable standard if opportunity sets are to be equivalent. ${ }^{23}$ For other capabilities, such as access to shelter and housing, what is most important is that each individual has access to a sufficiently good level of provision. GEO thus combines egalitarianism and sufficientarianism, depending on the good in question. Finally, the approach allows for resource differentials between 
different states, in relation, for example, to luxury goods, if (and only if) these differentials do not have an impact on GEO.

\section{FROM THEORY TO PRACTICE: SHOULD INSTITUTIONS IMPLEMENT GLOBAL EQUALITY OF OPPORTUNITY?}

Although GEO rests upon a claim about fairness that many will find intuitively

plausible, it is deeply controversial. One may oppose GEO for a number of reasons, six of which are listed here.

1. Unequal opportunities are not unfair even in a domestic context.

2. Unequal opportunities are unfair domestically but are not unfair internationally.

3. Although international inequalities are unfair, pursuing GEO would conflict with other morally valuable goals.

4. Although international inequalities are unfair, pursuing GEO would have undesirable effects in practice.

5. Although international inequalities are unfair, pursuing GEO would be impossible in practice.

6. Although international inequalities are unfair, there is little international public support for GEO and so pursuing GEO would lack democratic legitimacy.

These objections cover a wide range of different responses to GEO. Some stand as direct repudiations of the judgments at its heart; others are sympathetic to the project in some ways but are skeptical as to its costs, possibility, practicality, or legitimacy. Points 1 and 2 belong to the former category. With reference to Point 1 , some writers 
have denied that justice requires that equality of opportunity obtain in a domestic context: Libertarians, for example, might argue that the pursuit of equality of opportunity infringes on the rights of employers or property owners; consequentialists might argue that it leads to inefficient outcomes or does not maximize the good, however understood. ${ }^{24}$ This is clearly a profound difference of view. The case for GEO is unlikely to be persuasive to those who firmly reject equality of opportunity within particular communities. The debate concerning the circumstances of justice is at the heart of Point 2; as the previous discussion suggests, an affirmation of this item may represent a normative or an empirical dispute with the advocates of GEO. There is room for debate between defenders and opponents of GEO when disagreement hangs upon different empirical interpretations of the nature of international interaction, but in cases in which different parties simply affirm different models of the circumstances of justice, backed up, ultimately, by their deeply settled intuitive judgments, there is likely to be only so much that each side can do to persuade the other of the force of its argument.

What, then, of the objections made in Points 3 through 6? These remaining objections are more sympathetic to the ideal of GEO, in that they at least admit that there is something unfair about unequal international opportunity sets. Points 3 and 4 are related and will sometimes overlap in practice, insofar as the lack of pursuit of a valuable goal is in itself an undesirable effect. They are separated here to point out that one may advance a version of Point 3 at the abstract level of what justice or 
morality would require in a perfect world, without necessarily worrying about the concerns of practicality that arise in relation to Point 4.

The different types of argument that different approaches employ can be seen by considering the following argument from Rawls's The Law of Peoples. Rawls describes two imaginary societies, which begin from equal starting points and choose to follow divergent paths: One decides to industrialize and increase its rate of (real) saving; the other prefers a more pastoral and leisurely society. The result of this is that, decades later, the first country is twice as wealthy as the second. Rawls asks this question:

Assuming, as we do, that both societies are liberal or decent, and their people free and responsible, and able to make their own decisions, should the industrializing country be taxed to give funds to the second? According to the duty of assistance there would be no tax, and that seems right; whereas with a global egalitarian principle without target, there would always be a flow of taxes as long as the wealth of one people was less than that of the other. This seems unacceptable. ${ }^{25}$

As this stands, it is not clear why Rawls believes that such an outcome is unacceptable. He is advocating a world whereby peoples are held responsible for their actions across time, but this could be defended from a range of different perspectives. One could, for example, simply maintain that it is right for communities to be held responsible for the choices they make on the grounds that it would be unfair to tax others so as to ensure any kind of egalitarian distribution, even though it 
is justifiable to tax individuals within a given polity to ensure domestic equality of opportunity. Such a position would, for Rawls, be a version of Point 2, denying the unfairness of international inequalities specifically. Such a position might have a degree of plausibility if we conceive of the world in terms of a single generation, but it is much harder to maintain that fairness prohibits the taxation of later generations, who were not even born at the time of the economic decisions in question. Objections 3 and 4, however, accept that there is something unfair about allowing one's holdings to be determined by the actions of one's ancestors, but they deny that the unfairness in question is sufficiently important to require GEO. One might, for example, maintain that there is a particular value associated with national self-determination, possibly in similar fashion to how autonomy is deemed valuable for individuals. Such a claim is best expressed in terms of Objection 3: The idea is that the value of self-determination is sufficiently great to trump the value of the fairness achieved by GEO. Alternatively, one might simply maintain that such an international taxation scheme would be undesirable in practical terms, because, for example, there would seemingly be little or no disincentive against expensive consumption. Thus one might couch Rawls's argument in terms of the value of fairness, autonomy, or efficiency.

These are familiar concerns that typically also arise in domestic contexts. However, as in domestic contexts, they do not automatically trump arguments in favor of GEO, given an acceptance that international inequalities are unfair. The key point here is that, domestically, many people seem willing potentially to trade off efficiency for the degree of egalitarianism embodied in equality of opportunity. The 
idea is that although we may wish to hold particular individuals responsible for the choices that they themselves make, we nonetheless feel that we should structure society so as not to allow their choices to significantly affect the life chances of their children. This has obvious implications with regard to policy areas such as healthcare and education. The advocate of GEO need not deny that efficiency or national selfdetermination are valuable goals; the question is how valuable they are relative to the value of equality of opportunity. A full answer to this question would involve a complicated assessment of the costs and benefits of particular policy interventions, but for current purposes it is sufficient to see that one could coherently affirm that institutions should promote equality of opportunity despite Objections 1 through 4 if one was willing both to hold that international inequalities in relation to capabilities such as healthcare and education are unfair and to maintain that this unfairness is sufficiently serious as to outweigh other valuable goals that international institutions might seek to pursue.

Concern 5 is rather different - and seemingly poses a more fundamental challenge to the claim that GEO could operate as an institutional standard of distributive justice. Might it be the case that the comparison of opportunity sets in different countries and across different cultural contexts is actually impossible in practice? David Miller has pressed hard upon this point in seeking to oppose GEO. He argues that when seeking to assess different opportunity sets within a domestic context, we rely upon particular cultural understandings as to the value of different packages of opportunities. This is not possible, he argues, at a global level, where we 
struggle both to compare opportunities in relation to a particular dimension, such as education, given differing understandings of what education is, and particularly when we attempt to devise general metrics to compare overall opportunity sets. He uses the example of a comparison between the opportunity sets available to the inhabitants of Iceland and Portugal. Suppose we were to conclude that there were better leisure opportunities available in Portugal, but better educational opportunities in Iceland. Is this as far as the comparison can go, meaning that we can only say that they are each better according to two different metrics? Or can we make some kind of all-thingsconsidered claim about whether the citizens of one country or the other are better off? Miller argues that the latter course of action is not available to us, because in attempting to make such a claim "we run into serious difficulties created by the fact that we can no longer rely on a common set of cultural understandings to tell us which metric or metrics it is appropriate to use when attempting to draw crossnational opportunity comparisons."26

Is it really the case that we can therefore never say that opportunity sets are unequal? Miller anticipates a response to his position: "Global egalitarians... will probably respond that the most urgent cases are cases of gross inequality where no reasonable person could doubt that the resources and opportunities open to members of A are superior to those available to members of B." ${ }^{27}$ Thus the real issue is not one of comparisons between countries such as Iceland and Portugal, but between, for example, developed EU member states and sub-Saharan African countries. In such cases, it appears that we can plausibly make the claim that opportunity sets are 
unequal without having to resolve the more difficult issues raised by the IcelandPortugal comparison.

Miller makes two observations in relation to this claim. The first is that the possibility of an identification of unequal opportunity sets in such cases "does not mean that in general we are in a position to make such inter-societal comparative judgments, either within the group of rich societies or within the group of poor societies, and so although we might be able to identify the most egregious forms on inequality, we remain unable to specify what equality (of opportunity) would mean." Second, in such cases we are typically looking at situations in which sufficientarians would agree that disadvantaged persons are victims of injustice, because they lack access to minimal conditions for decency and flourishing. In this way, it may be the absolute levels of disadvantage that are doing the work in terms of our judgment of injustice. There is a practical point here, in that the judgment of injustice is overdetermined, meaning that there can be broad agreement that remedial action is necessary, but also a normative point that, in extreme cases, "what seems at first sight to be a concern about inequality may well turn out on closer inspection to be a concern about absolute poverty or deprivation, a concern which suggests a quite different general understanding of global justice."28

Need advocates of GEO oppose these claims? This depends upon whether GEO is merely being defended as an element of the best ideal-type theory of international distributive justice or is being advocated as a goal that should guide real-world policy makers. The idea that it is unfair that different individuals have 
access to unequal opportunity sets is compatible with the claim that in some cases we will not be able to tell which individuals are advantaged relative to others. This will be so where we simply lack sufficiently nuanced data to make a meaningful comparison, and we may even concede that it is so when the different cultural meanings that are attached to goods by different societies make some kinds of comparison between opportunity sets impossible or meaningless. So, in fact, it would be possible both to defend GEO as the best philosophical account of what global distributive justice is, but also maintain that it is not possible, in practice, to determine to what extent the world is actually just or unjust, based on the difficulty of making international comparisons. However, this would be an extreme conclusion to draw from the acknowledged fact that in some cases making comparisons is likely to be problematic. There are two ways in which one might maintain that it is possible to identify gross inequalities, but that judgments are not possible when different opportunity sets are less manifestly unequal.

The first is the possibility considered by Miller, in considering citizens of Niger and France, where he suggests that the opportunity sets available to citizens of the former may be "strictly smaller" than the sets available to citizens of the latter, in the sense that there may be no basic dimension of, for example, the Human Development Index ${ }^{29}$ in which citizens of Niger outscore citizens of France. In such a case, we do not have to consider how to trade off one dimension against the other, as in the leisure versus educational opportunities case: The suggestion is that there may be no plausible dimension in terms of which the average Niger citizen outscores the 
average France citizen. Miller is only committed to accepting that inequality obtains in such cases.

We should also maintain, however, that it is possible to make comparisons even when some balancing of dimensions is required. The suggestion that in some cases it will not be possible to say which opportunity set is better because of the difficulty of comparing different dimensions does not necessarily lead to the conclusion that it is always impossible to make overall comparisons between different opportunity sets. The Iceland-Portugal comparison seems troubling to us because there seems to be a real danger that we will go wrong in attempting to maintain that the citizens of one country or the other are better off in an all-thingsconsidered sense. But imagine, instead, that we are comparing two countries with manifestly different degrees of economic development. In all but one dimension, say leisure opportunities, Country A is clearly much more advantaged than Country B, whereas Country B is marginally better off in this single dimension. We might further stipulate that all the members of A and all the members of B regard the opportunity sets of Country A's citizens as superior to those of Country B's citizens. In such a case it does seem clear that there is inequality of opportunity and the advocate of GEO will be able to point to redistributive policies that will make the situation more just. It should be stressed that this claim is perfectly compatible with the claim that it may not be possible to pursue such policies to the point where injustice no longer obtains. The key point here is that as a regulative ideal, GEO can be interpreted in a positive and a negative fashion. The positive approach would 
claim that institutions should actively seek to bring about GEO. The negative approach instead maintains that institutions should seek to minimize or remove identifiable inequalities in opportunity sets between the citizens of different states. The difference is that the negative approach can accept that institutions should only act in response to what appear to be obvious inequalities in opportunity sets. Thus, it may be better to maintain that international institutions should oppose global inequality of opportunity, rather than seeking to achieve equality of opportunity. This is how institutions concerned with domestic equality of opportunity typically operate. In an employment context, the ideal of equality of opportunity requires that jobs be awarded to the most meritorious candidate, without reference to attributes that do not relate to job performance. Bodies, such as courts, which seek to uphold this ideal cannot expect or be expected to be able to scrutinize all hiring decisions to ensure that this ideal is achieved; instead the judgments of those responsible for hiring are generally respected unless there is evidence of an egregious breach of equality of opportunity, on grounds, for example, of race or sex. No doubt in many hiring cases it will be impossible to say definitively that one candidate is better qualified than another specific candidate, either because those responsible for hiring lack sufficiently nuanced data upon which to make their judgment, or because different candidates have different strengths and weaknesses, meaning that there is no fact of the matter as to which is the most meritorious. This does not mean, however, that there will not be cases in which it is obvious that those responsible for employment 
decisions have violated the principle of equal opportunity, and, in such cases, we often feel it is appropriate for judicial institutions to intervene.

To be clear, none of this is to deny that comparing opportunity sets between different cultures will often be a problematic business. Given the very real variation we find in different cultures as to the meaning and values of particular social positions, assessing when equality of opportunity is and is not being achieved will be difficult in practice. Gillian Brock, for example, has stressed the dangers involved:

Either we must articulate a version of equality of opportunity that mentions particular social positions that are favored and opportunities to occupy these positions are equalized, or we allow much cultural variation about what counts as a favored social position and it is now the standards of living or levels of well-being that they enable that are to be equalized. If we go with the first option, we are vulnerable to charges of being insufficiently attuned to cultural difference. If we go with the second and try to equalize standards of living, we may end up with an account of equality of opportunity too weak to rule out disadvantage and discrimination on morally arbitrary grounds. ${ }^{30}$ It is quite right to note that advocates of GEO need to be attentive to these considerations. It is not at all clear, though, that they should lead us to abandon a concern for GEO. A coherent account of GEO will have to be sensitive to the fact that different jobs have different meanings in different cultures, but will also have to have at least some kind of external critical analysis of the value that different positions actually afford to individuals within the culture. This is a familiar problem 
within political theory. The proliferation of different cultures across the world certainly makes intercultural judgments and comparisons difficult, and it reminds us that we need to take careful account of different cultural understandings.

Nevertheless, short of withdrawing into a fully fledged model of cultural relativism, it is unclear what else we can do other than to combine respect for other ways of doing things with an acknowledgment that the mere fact that a culture believes something to be right or good does not automatically make it right or good.

Thus it is not clear that advocates of GEO really do face a dilemma whereby they must either ride roughshod over different cultural understandings or give in to relativism as to the good. There will certainly be difficult questions to be answered when particular cultural traditions seemingly afford a different weight to opportunity sets than that attributed to them by externally derived schedules of capabilities, and any solution is indeed likely to be criticized from the external or internal perspective, if not from both. The challenge for the advocate of GEO is to defend the answer she or he gives to this question - but this is not to say either that the question is unanswerable, or that it emerges in all international comparison of opportunity sets. In particular, we might consider one crude way to track gross inequality between opportunity sets by looking at the extent to which people in one country seek to migrate to other countries. ${ }^{31}$ In a world characterized by GEO, where the state where one resides does not make a difference to the value of one's opportunity sets, we would expect that people would want to move in and out of particular states to a roughly equal extent. This is not to say that the presence of such an equilibrium 
would mean that GEO had been obtained, as there are many reasons why people may not wish to leave the state where they grew up and where most of their family and friends reside, even if they know that by migrating they would have access to superior opportunity sets. ${ }^{32}$ However, the absence of such an equilibrium would provide at least prima facie evidence for the claim that opportunity sets are not equal in different communities. There is nothing in such an analysis that involves disrespect for different cultural traditions. The claim is rather that inequality obtains according to the evaluations of the members of the disadvantaged cultures in question. The advocate of GEO should be troubled both by the inequality of opportunity sets that this disequilibrium indicates, and by the extent to which existing immigration controls prevent those living in disadvantaged areas seeking to improve their prospects by relocating.

Finally, although Miller is surely right to note that, in some cases, the immediate intuitive response to cases of deprivation will be grounded in concern for absolute rather than relative levels of well-being, this is not to say that this is the only normatively powerful concern in play in cases of global inequality. The advocate of GEO can insist that inequalities are troubling even when they operate above the threshold level of sufficientarian concern. The point is that for such a person the reaction is overdetermined. GEO advocates need not dismiss sufficientarianism altogether: As Paula Casal has argued, it is possible to maintain that sufficiency thresholds have a part to play in questions of distributive justice without maintaining that they tell the full story of distributive justice. ${ }^{33}$ GEO advocates need not deny that 
the most troubling and pressing problems of distributive justice are those in which individuals lack access to basic resources; their claim is simply that the level of absolute deprivation is not solely constitutive of the situation's injustice, even if it is its most pressing part. It may well be that, in the current world, both sufficientarians and GEO advocates would agree on what measures should be taken in the short term to remedy the world's most serious injustices.

What advocates of GEO should not do is to give up on the idea of equality of opportunity and fall back on sufficientarian accounts that focus on absolute rather than relative disadvantage (bolstered, perhaps, by alternative egalitarian principles, such as that of democratic equality). The advocate of GEO can concede a certain amount to her or his critics without forsaking the deep egalitarian intuition that it is unfair if the place of one's birth makes a difference to how well one's life goes. She or he can accept that addressing the urgent needs of the world's poorest people is the most important task we face. The advocate can accept that this need not rest upon any kind of idea of equality to be normatively compelling, and that we should not pursue equality if such a pursuit in any way involves a trade-off of the interests of those in desperate need. She or he can further accept that perfect GEO is unrealizable in practice, that its practical pursuit will be limited to intervening to prevent the most obvious instances of inequality, and that many of these interventions could, for the foreseeable future, be justified by reference to sufficientarianism. Nonetheless, this advocate should reject vehemently the idea that the achievement of this task would result in a just world order. Many people care desperately about equality of 
opportunity at a domestic level, even in affluent states with reasonably well-working welfare states, and find it deeply unjust if, for example, the existence of a two-tier education or healthcare system means that those who have richer parents have better prospects in life. For the cosmopolitan, such inequalities should be just as troubling on a global level. Pursuing GEO may be more difficult in practice than pursuing its domestic counterpart, but there is nonetheless much that can be done to reduce international inequalities for equality's sake. The difficulty of doing so is not sufficient reason to accept sufficientarianism alone.

\section{COSMOPOLITANISM AND LEGITIMACY}

What, then, of Objection 6, which queries the democratic legitimacy of GEO? For those who oppose GEO and seek to uphold noncosmopolitan accounts of international distributive justice, even if they accept sufficientarian duties of assistance, this question is much less problematic. Insofar as they advocate conservative principles of distributive justice, their prescriptive claims typically approximate to contemporary settled norms of international justice, as embodied in international law and mainstream international rhetoric, if not in actual international practice. In this way, it appears as if the justification for their position is backed by both normative argumentation and democratic consensus. The difficult question, then, comes for those who believe that the best philosophical principles of international distributive justice are transformative in nature. What should be done if normative argumentation points in one direction, but popular sentiment in another? This raises two questions: 
1. Do international institutions act legitimately in seeking to implement global equality of opportunity?

2. Even if we deem such action to be illegitimate, should international institutions, in an-all-things considered sense, act to implement GEO?

Answering Question 1 negatively does not answer Question 2, because there might be cases in which the injustice of not intervening trumps concerns of legitimacy. This can be seen in relation to interventions to protect basic rights: There is no inconsistency in thinking, for example, that international bodies lack legitimacy in intervening in the affairs of sovereign states in order to uphold such rights, but maintaining that they should nonetheless so intervene. Question 2 might be answered negatively for one of two reasons, either based on the wrongness of illegitimacy, with reference to democratic principle, or on the practical effects of illegitimacy, such as, for example, in relation to the future capacity for intervention of the institution in question. A full consideration of either question largely lies beyond the scope of this chapter. However, as an initial response, the following points may be made.

First, the nature of the international institution in question is clearly significant. We might, for example, separate governmental and nongovernmental institutions, and we might note that particular questions of legitimacy obtain in relation to the former, because they operate, in some sense, at the behest of a demos, or of multiple demoi. This is not to say that no questions of legitimacy arise in 
relation to the nongovernmental organizations (NGOs); much has been written of the propriety of interventions by Western NGOs in the affairs of less developed countries, ${ }^{34}$ and there are also issues relating to how their actions relate to the views of their members and supporters. Nonetheless, there is prima facie plausibility to the idea that NGOs should generally be free to promote GEO, particularly in cases where doing so is in accordance with views of their membership and does not involve unwanted interference.

The case of governmental institutions is more complicated. Is it justifiable for such bodies to base their decisions in politically controversial accounts of justice, which, let us say for the sake of argument, are not endorsed by a majority of their demos? A straightforward populist account of democratic legitimacy would give way on all occasions to the majority, but most accounts are rather more nuanced than this and pay attention to the particular office of the agent charged with decision making be they elected legislator, appointed judge, bureaucrat, or soldier. For example, Cass Sunstein argues that the rule of law constrains official decision making, and so "tries to prevent people in particular cases from invoking their own theories of the right or the good so as to make decisions according to their own most fundamental judgments." 35 Thus, the rule of law rules off limits "deep ideas of the right or the good," and it holds that such ideas ought not usually be invoked by judges and officials. But the claim that these sorts of agents should not act upon their best understanding of what should be done does not necessarily apply to all decision makers; "we might make distinctions between the role of high theory within the 
courtroom and the role of high theory in the political branches of government... in democratic arenas, there is no taboo, presumptive or otherwise, on invoking high level theories of the good or the right." ${ }^{36}$ If this is accepted then it opens the way to a legitimate pursuit of GEO, at least to international institutions that can claim their own democratic mandate. The most notable are international legislatures such as the European Parliament, and bodies composed of different actors with their own national mandates, who come to possess legitimacy in an international context when acting collectively.

What, though, of the harder case of international institutions that are appointed by governments, and so are in this sense governmental, but that do not possess their own independent democratic mandates? Take, for example, international courts. It is often maintained that it is legitimate for courts to override majoritarian decision making when majorities threaten individuals' basic rights. However, it is far more controversial to argue that courts should intervene in such a way as to further a contentious principle of distributive justice, such as, for example, egalitarianism. This is not to say that courts should never act in such a way. A striking recent example of a justification for the courts acting in such a manner comes from South Africa, where Chief Justice Pius Langa has argued that the South African courts should be guided by a principle of "transformative constitutionalism" whereby the courts are committed to creating a substantively equal society, defined both in terms of the prevention of discrimination and also, strikingly, the promotion of distributive justice. He speaks explicitly of "the leveling of the economic playing 
fields that were so drastically skewed by the apartheid system," and he claims that the constitutionally required transformation of South African society "does not only involve the fulfillment of socio-economic rights, but also the provision of greater access to education and opportunities through various mechanisms, including affirmative action measures." ${ }^{, 37}$ It may be noted, however, that the South African context is highly unusual. Langa's defense of transformative constitutionalism rests not solely upon a philosophical defense of egalitarianism, but also on both South Africa's particular political history of apartheid and on the extraordinarily extensive process of public consultation that fed into the new South African constitution. To argue that a judicial institution, without a comparable democratic mandate, should act in such a fashion is certainly controversial.

Two points, then, may be made in relation to the legitimacy of the pursuit of GEO by international institutions that lack their own direct mandate. First, as has already been noted, it may well be that in practice sufficientarians and egalitarians agree as to the first moves that such institutions should be making to secure individuals' most basic needs. We are still a long way from the realization of sufficientarianism, and this creates a window of opportunity for political campaigns to build popular majorities in favor of GEO. It may well be that given the philosophically controversial nature of GEO, it will not be possible to reach a point where support for GEO is consensual in the same way that is increasingly the case for basic rights claims, but there is still the potential for an agonistic approach to international democracy, whereby cosmopolitans seek to win over a sufficient 
portion of popular opinion to implement their principles through majoritarian means. ${ }^{38}$ In this view, cosmopolitans should focus on building popular majorities in favor of equal access to those capabilities such as healthcare and education that are critical to GEO. International institutions can legitimately intervene to implement GEO when backed by popular majorities of this kind.

Second, and potentially more radically, it was previously noted that the question of the legitimacy of an institutional intervention is not the same as the question of whether such an intervention is justified. ${ }^{39}$ A belief that a given action is illegitimate does not necessarily lead to the view that that action should not be fulfilled if legitimacy is seen as a desideratum, rather than a sine qua non, of institutional action. Thus it would be possible for an advocate of GEO to accept that furthering GEO is not legitimate but nonetheless maintain that, in an all-thingsconsidered sense, it ought to take place. The readiness of such an advocate to argue in this way will depend upon the amount of weight he or she affords to institutional legitimacy, and in particular to whether this is seen as intrinsically good for reasons of democratic principle or simply instrumentally valuable for the achievement of particular good outcomes. Thus domestically, one might oppose judicial activism on the grounds that it is wrong for courts to assume a law-making function that properly belongs to legislatures as a matter of democratic principle, or on the grounds that courts damage their ability to bring about other good outcomes by risking losing popular support in acting without legitimacy. The more critical the interests being 
served by transformative institutional action, the more justifiable it is for institutions to disregard public opinion.

It might be noted, by way of conclusion, that we should not assume that the same considerations that are taken to be compelling in a domestic context will necessarily apply in an international setting. Questions of legitimacy are easier to settle in state-centered democracies, where elected officials possess relatively straightforward mandates from a given demos. To be sure, a host of problems arise when we try to speak meaningfully of the way in which such a mandate corresponds realistically to the will of the people given the real-world circumstances of contemporary representative democracies, and such reasons may well lead us to query whether illegitimate action is wrong for reasons of democratic principle even in state-centered contexts. According to this perspective, the legitimacy-based concerns facing international institutions are largely pragmatic and prudential in nature. Such problems are amplified in an international context, where law making and governance emerges from a much more complicated process of decision making, involving a wide range of both elected and unelected bodies, with seriously disputed democratic legitimacy.

For many, the value of democracy in real-world contexts lies not in the way it translates the will of the people into public policy, but in the way it authoritatively settles the question of who should wield political power. From such a perspective, domestic illegitimacy may be problematic in a way that does not arise in the same fashion in an international context. An international institution that seeks to further 
GEO may be going against public opinion, but this does not threaten to challenge or undermine socially beneficial democratic institutions in the same way that similar action could in the domestic sphere. It may still be that reasons of prudence and pragmatism may counsel institutions against the promotion of GEO - but the point here would not necessarily be that such action would be illegitimate and thus wrong, but rather that bad outcomes would result from a popular perception that the institution in question was acting illegitimately. Such a judgment would obviously be particular to the case in question, and it leaves open the possibility of a conclusion that given institutions should indeed, in an all-things-considered sense, promote global equality of opportunity.

* This paper was originally given at a symposium of the International Legal Theory Interest Group of the American Society of International Law, in Washington DC, I am grateful to the participants at this event, and to the editors of this volume, for their very helpful feedback..

${ }^{1}$ See Rawls's account of his work as "realistically utopian," in John Rawls, The Law of Peoples (Cambridge, MA: Harvard University Press, 1999), 6-7.

${ }^{2}$ See G. A. Cohen, Rescuing Justice and Equality (Cambridge, MA: Harvard University Press, 2008).

${ }^{3}$ John Rawls, A Theory of Justice (Oxford: Oxford University Press, 1972), 3. 
${ }^{4}$ See Richard Wollheim, "A Paradox in the Theory of Democracy," in P. Laslett and W. G. Runciman (eds.), Philosophy, Politics and Society: Second Series (Oxford: Blackwell, 1962), 71-87.

${ }^{5}$ John Rawls, Political Liberalism (New York: Columbia University Press, 1995). For discussion, see T. M. Scanlon, "Rawls on Justification," in Samuel Freeman (ed.), The Cambridge Companion to Rawls (Cambridge: Cambridge University Press, 2002), 157-166.

${ }^{6}$ See Richard Arneson, "Equality of Opportunity," in Edward N. Zalta (ed.), The Stanford Encyclopedia of Philosophy, Fall 2008 edition (available at http://plato.stanford.edu/archives/fall2008/entries/equal-opportunity/).

${ }^{7}$ Arneson, "Equality of Opportunity."

${ }^{8}$ Samuel Freeman, Justice and the Social Contract: Essays on Rawlsian Political Philosophy (New York: Oxford University Press, 2007), 117n.

${ }^{9}$ Rawls, A Theory of Justice, 73.

${ }^{10}$ Rawls, A Theory of Justice, 302.

${ }^{11}$ Joseph H. Carens, "Migration and Morality: A Liberal Egalitarian Perspective," in B. Barry and R. Goodin (eds.), Free Movement: Ethical Issues in the Transnational Migration of People and of Money (Hemel Hempstead: Harvester Wheatsheaf, 1992), 26.

${ }^{12}$ John Rawls, The Law of Peoples, 119. 
${ }^{13}$ The terminology of relational and nonrelational theories is taken from Andrea Sangiovanni, “Global Justice, Reciprocity and the State," Philosophy and Public Affairs 35 (2007): 6.

${ }^{14}$ Darrel Moellendorf, Cosmopolitan Justice (Boulder, CO: Westview Press, 2002), 32.

${ }^{15}$ Michael Blake, “Distributive Justice, State Coercion, and Autonomy,” Philosophy and Public Affairs 30 (2002): 258.

16 Thomas Nagel, "The Problem of Global Justice," Philosophy and Public Affairs 33 (2005): 128-129.

${ }^{17}$ See Daniel Butt, Rectifying International Injustice: Principles of Compensation and Restitution Between Nations (Oxford: Oxford University Press, 2009), 115117.

${ }^{18}$ Moellendorf, Cosmopolitan Justice, 49.

${ }^{19}$ See David Miller, National Responsibility and Global Justice (Oxford: Oxford University Press, 2007), 62.

${ }^{20}$ Simon Caney, "Cosmopolitan Justice and Equalizing Opportunities," Metaphilosophy 32 (2001): 120.

${ }^{21}$ Sylvia Loriaux, "Global Equality of Opportunity: A Proposal,” Journal of International Relations and Development 11 (2008): 2.

${ }^{22}$ Martha C. Nussbaum, and Amartya Sen (eds.), The Quality of Life (Oxford: Clarendon Press, 1993). 
${ }^{23}$ This builds upon, but goes beyond, the approach to the right to the highest attainable standard of health articulated by the UN Committee on Economic, Social and Cultural Rights in General Comment 14. See Paul Hunt, "The Millennium Development Goals and the Right to the Highest Attainable Standard of Health," The John D. and Catherine T. MacArthur Foundation International Lecture Series on Population Issues, Abuja, Nigeria (available at http:/www.macfound.org/atf/cf/\%7BB0386CE3-8B29-4162-8098E466FB856794\%7D/HUNT_POPULATION.PDF).

${ }^{24}$ See Richard Epstein's argument that antidiscrimination laws are unjustified on consequentialist grounds: "[T]here is no reason to believe that this antidiscrimination system generates additional benefits that exceed its costs, social or economic.” Richard A. Epstein, Forbidden Grounds: The Case against Employment Discrimination Laws (Cambridge, MA: Harvard University Press, 1992), 27.

25 John Rawls, The Law of Peoples, 117.

${ }^{26}$ Miller, National Responsibility and Global Justice, 66.

${ }^{27}$ Ibid., 67.

${ }^{28}$ Ibid., 68.

${ }^{29}$ The Human Development Index ranks states by a formula that includes three dimensions: life expectancy at birth; knowledge and education; and standard of 
living. See http://hdr.undp.org/en/media/hdr_20072008_tech_note_1.pdf (accessed April 4, 2009).

${ }^{30}$ Gillian Brock, Global Justice: A Cosmopolitan Account (Oxford: Oxford University Press, 2009), 61-62.

${ }^{31}$ Note that this is not the same as the extent to which people do in fact migrate in the real world, because of the presence of immigration restrictions.

${ }^{32}$ It is for this reason that removing immigration controls would not be sufficient for the realization of GEO. See Kieran Oberman, "Immigration and freedom of movement" (Oxford D. Phil. thesis, 2009).

${ }^{33}$ Paula Casal, “Why Sufficiency Is not Enough,” Ethics 117 (2007), 296-326.

${ }^{34}$ See Terry Macdonald, Global Stakeholder Democracy: Power and Representation Beyond Liberal States (New York: Oxford University Press, 2008).

${ }^{35}$ Cass Sunstein, Legal Reasoning and Political Conflict (Oxford: Oxford University Press, 1996), 44.

${ }^{36}$ Sunstein, Legal Reasoning and Political Conflict, 45.

${ }^{37}$ Pius N. Langa, “Transformative Constitutionalism," Stellenbosch Law Review 17 (2006): 352 .

${ }^{38}$ Chantal Mouffe, "For an Agonistic Model of Democracy," in Noel O’Sullivan (ed.), Political Theory in Transition (London: Routledge, 2000), 113-130.

${ }^{39}$ See A. J. Simmons, "Justification and Legitimacy," in Justification and Legitimacy: Essays on Rights and Obligations (Cambridge University Press, 2001), 122-157. 